\title{
KETEN TOHUMU YAĞI VE AYÇIÇEK YAĞINDAN FARKLI VAKSLAR KULLANILARAK OLUŞTURULAN OLEOJELLERİN BİSKÜVİ KALİTESİ ÜZERİNE ETKÍLERİ
}

\author{
Kübra Sultan Özdemir ${ }^{*}$ \\ Gıda Mühendisliği Bölümü, Mühendislik ve Mimarlık Fakültesi, Konya Gıda ve Tarım Üniversitesi, Konya, \\ Türkiye
}

Geliş / Received: 31.07.2021; Kabul / Accepted: 06.09.2021; Online bask1 / Published online: 22.09.2021

Özdemir, K.S. (2021). Keten tohumu yağı ve ayçiçek yağından farklı vakslar kullanılarak oluşturulan oleojellerin bisküvi kalitesi üzerine etkileri. GID A (2021) 46 (5) 1279-1288 doi: 10.15237/gida.GD21108.

Özdemir, K.S. (2021). Effect of sunflower oil and flaxseed oil based oleogels formed by different waxes on the quality of biscuits. GID A (2021) 46 (5) 1279-1288 doi: 10.15237/gida.GD21108.

\section{ÖZ}

Yağlar insan beslenmesinin temel bileşenlerden biri olup, enerji kaynağı olması ve gida ürününün lezzet ve tekstürünü geliştirmesi, bazı vitamin, biyoaktif bileşen gibi maddeler için taşıyıcı olmasından dolayı oldukça önemlidir. Ancak katı yağların sağlık üzerine muhtemel zararlanı nedeni ile ikame olarak oleojel kullanımı önerilmektedir. Bu çalsșmada, balmumu, kandelila ve karnauba vaks ile keten tohumu yağı ve ayçiçek yağı kullanılarak oleojeller üretilmiş, sonrasında bu oleojeller geleneksel bisküvi kompozisyonunda katı yă ikamesi olarak kullanılmıştır. Oleojellerin yağ bağlama kapasitesi ile bisküvilerde renk, çap, kalınlık, yayılma oranı gibi fiziksel özellikler ve tekstürel özellikler incelenmiştir. En yüksek yağ bağlama kapasitesi kandelila vaks ile üretilen oleojellerde tespit edilmiştir. Keten yağı oleojellerinin \%50 oranında şortening yerine kullanılmasıyla üretilen bisküvilerde sertlik değeri kontrole göre önemli derecede azalırken, \%100 ayçiçek yağ1 oleojeli ile ikame edilen bisküvilerde önemli bir fark gözlenmemişsir.

Anahtar kelimeler: Oleojel, karnauba vaks, balmumu, kandelila vaks, bisküvi, tekstür

\section{EFFECT OF SUNFLOWER OIL AND FLAXSEED OIL BASED OLEOGELS FORMED BY DIFFERENT WAXES ON THE QUALITY OF BISCUITS}

\begin{abstract}
Fats are one of the basic components of human nutrition and are very important because they are a source of energy, improve the flavor and texture of the food product, and are carriers for some vitamins and bioactive components. However, the use of oleogels is recommended as a substitute due to the possible health risks of solid fats. In this study, flaxseed and sunflower oil based oleogels were produced with beeswax, candelila and carnauba wax and these oleogels were used as a shortening substitute in traditional biscuit composition. The oil binding capacity of oleogels, color, diameter, thickness, spread ratio and textural properties of biscuits were investigated. The highest oil binding capacity was determined in candelila wax oleogels. While the hardness value of the biscuits produced with flaxseed oil oleogels $(50 \%)$ decreased significantly compared to the control, no significant difference was observed in the biscuits replaced with $100 \%$ sunflower oil oleogels.
\end{abstract}

Keywords: Oleogel, carnauba wax, beeswax, candelilla wax, biscuit, texture

\footnotetext{
${ }^{*}$ Yazışmalardan sorumlu yazar / Corresponding author

17: kubrasoz@gmail.com

(ग): (+90) 3322235447

圆: (+90) 3322235490
}

Kübra Sultan Özdemir; ORCID no: 0000-0002-7428-1840 


\section{GİRİ̧}

Yağlar, g1da ürününün lezzet ve tekstürünü geliştirmek veya modifiye etmek, hamur ürünlerinin mayalanmasi, emülsifikasyon, kızartma, pişirme gibi uygulamalarda 1sı transferini sağlamak ve yapışmayı önlemek gibi fonksiyonlara sahiptir (Vaclavik ve Christian, 2014). Ayn1 zamanda, sıvı ve katı yağlar, insan beslenmesinde önemli bir enerji kaynağı olmalarının yanı sıra vitaminler ve biyoaktif bileşenler için çözücü ve taşıyıc1 özelliği göstermektedirler (Pehlivanoğlu vd., 2018). Bu nedenlerden ötürü yağlar, gida ürününün hem yapısal-duyusal özellikleri üzerinde hem de besinsel özelikleri üzerinde önemli rol oynamaktadır. Gıda endüstrisi, yağların önemini fark ettikten sonra, daha ucuz yöntemlerle sıv1 yağlardan katı yağ üretebilme yollarını araştırmaya yönelmiştir. Bu amaçla farklı yöntemler geliştirilmiş olup, hidrojenizasyon, interesterifikasyon, fraksinasyon metotlar1 yaygin kullanılan metotlardır. Günümüzde, yapılandırılmış katı yağlar yaygın olarak margarin ve sürülebilir kahvaltıllk ürünlerde, firnncilık ürünlerinde ve çikolata ürünlerinde kullanilmaktadir.

Yapılandırılmış katı yağların gıda ürünlerinde kullanılması, beslenme ve sağlık ilişkisi konusunda bilinçli tüketicilerde iki açıdan endişe yaratmaktadır. Bu endişelerden biri, bu tür katı yağların daha yüksek doymuş yağ asidine sahip olmasıdır. Doymuş yağ asitlerinin yüksek miktarda tüketilmesi sonucu, kalp ve damar hastalıkları, obezite ve diyabet riski artmaktadır. $\mathrm{Bu}$ nedenle Dünya Sağlık Örgütü (WHO) tarafından, günlük diyette alınması gereken enerjinin yaklaşı \% \%10'unun doymuş yağlardan sağlanmas1 önerilmektedir. Bir diğer endişe ise, bitkisel sıvı yağların katılaştırılması sırasında, interesterifikasyon ile oluşan trans yağ asitleridir. Trans yağ asitlerinin, koroner kalp hastalıkları, kanser ve diyabet gibi kronik rahatsızlıkların ortaya çıkma oranını arttırdığı ve kan lipoproteinleri üzerine zararlı etkilerinin olduğu bilinmektedir (Brouwer vd., 2010; Mozaffarian vd., 2009; Uauy vd., 2009). Bu nedenle, günümüzde araştırmacılar ve gida endüstrisi uzmanları, bitkisel sıv1 yağların katı yağa dönüştürülmesinde sağllk açısından risk oluşturmayan yeni yollar aramaktadır. Ayrıca gıda ürünlerindeki doymuş yağ ve trans yağ asidi miktarını azaltırken, gıdanın fizikokimyasal ve duyusal özelliklerini koruyabilen yöntemler bulmanın oldukça zor olduğu bilinmektedir. (Iqbal vd., 2019). Bu noktada, doymuş yağ asidi içeriğini azaltma hususunda gelecek vadeden yollardan birisi, formülasyonlarda oleojel kullanımıdır.

Oloejeller; bitkisel mumlar, monodigliseritler, yă asitlerinin alkolleri veya esterleri, fosfolipidler ve fitosteroller gibi oleojelatörler kullanılarak sıv1 yağın oleojelasyonuyla hazırlanan yapılandırılmış yağlardır (Pérez-Monterroza vd., 2014). Ayrica oleojeller, üç boyutlu bir jel yapısı içerisinde hapsedilmiş organik likit olarak da tanımlanmaktadır (Öğütcü ve Yılmaz, 2015). Son yıllarda, oleojel ile ilgili bulgular ve çalışmalar artmakta olup oleojellerin farklı gida formülasyonlarında (kek, bisküvi, çikolata, et ürünleri vb.) doymuş yağın azaltılmasına yönelik kullanılabilirliği ile ilgili pek çok çalışma rapor edilmiştir (Park ve Maleky, 2020; da Silva vd., 2019). Literatürdeki çalışmalara göre, son ürün kalite özelliklerini koruyabilmek için oleojellerin kullanım miktarının belirli limitler çerçevesinde olması gerektiği bildirilmiştir. Aynı zamanda, oleojel kullanımının dolgulu çikolata gibi ürünlerde yağ taşınımı engelleyebildiği ve böylece çikolatada önemli bir problem olan yağ çiçeklenmesini önleyebileceği ile ilgili çalışmalar mevcuttur (Hughes vd., 2009).

Oleojellerin oluşturulmasında genellikle lipit temelli materyaller kullanılmakta olup son yıllarda farklı hidrokolloidlerin kullanıldığ $\mathrm{da}$ görülmektedir. $\mathrm{Bu}$ maddeler oleojelatör (jelleştirme ajanı) olarak isimlendirilmektedir. Oleojelatörler arasında vakslar (balmumu, kandelila, karnauba vb.), monodigliseritler, triaçilgliseroller (TAG), diaçilgliseroller (DAG), monoaçilgliseroller (MAG), yağ asitleri, yağ alkolleri, vaks esterleri, sorbitan mono-stearat, etil selüloz ve bunların karışımları sayılabilir (Zetzl vd., 2012). Oleojelatörler, oleojelin fizikokimyasal özelliklerini (örneğin opaklık, tekstür, erime sıcaklığı, yağ bağlama kapasitesi vb.) etkilemektedir (Singh vd., 2017). Bununla birlikte, 
oleojel oluşturulmasında kullanılan yağın kimyasal özellikleri (yağ asiti profili) ve oleojel oluşturma yöntemleri de oleojelin yapisal özelliklerini etkilemektedir (Patel ve Dawettinck, 2016; Singh vd., 2017).

Atıştırmalık ürünler arasında bisküviler oldukça popüler olup farklı kesimlerden tüketiciler tarafindan yaygın olarak tüketilmektedir. Bisküvi kalitesini etkileyen en önemli bileşenlerden birisi şorteninglerdir. Ancak şortening kullanımı, yüksek miktarda doymuş ve trans yağ alımına neden olmaktadır. $\mathrm{Bu}$ nedenle yenilebilir oleojellerin firıncılık ürünlerinde kullanımı ile ilgili olarak çeşitli çalışmalar yapılmıştır. Yapılan bir çalışmada, \%15-45 arasında şortening yerine balmumu oleojelleri kullanilarak bazı firincilık ürünleri üretilmiş ve orijinal ürünlerle özellikleri karşılaştırılmıştır (Demirkesen ve Mert, 2019). Çalışma sonucunda, şorteningin oleojel ile kısmi değişimi ile kabul edilebilir özelliklerde glutensiz kek ürününde doymuş yağ oranını yaklaşı $\% 35$ oranında azaltabilmişlerdir. Oleojel oluşturmak için kanola yağı ve farklı oranlarda (\%3 ve \%6) kandelila vaksının kullanıldığı bir başka çalışmada ise bisküvi yapısındaki yağın tamamen oleojellerle değiştirilmesinin bisküvilerin sertliğini artırdığ belirlenmiştir. Bu nedenle, bisküvi formülasyonundaki yağın ancak kısmi olarak olejollerle değiştirilmesinin uygun olduğu sonucuna varılmıştır (Mert ve Demirkesen, 2016). Jang vd. (2015) kanola yağı ve farklı oranlarda kandelila vaks1 (\%3 ve \%6) kullanarak oluşturdukları oleojelleri doymuş yağ oranını azaltmak amacıyla bisküvi formülasyonuna eklemişlerdir. $\mathrm{Bu}$ çalışmada, bisküvilerin doymamış yağ asidi içeriği $\% 47.2$ 'den \%92'ye yükseltilirken doymuş yağ içeriği ise $\% 52.8$ 'den $\% 10$ 'a kadar düşürülmüştür.

Bu çalışmanın amacı, farklı oleojelatörler ve yağlar kullanılarak hazırlanan oleojellerin bisküvi kalitesi üzerindeki etkilerini karşılaştırmak ve oleojellerin fiziksel özellikleri ile bisküvi kalitesi arasındaki ilişkiyi incelemektir. Bu amaçla, keten tohumu yağı ve yüksek oleik asitli ayçiçek yağından, balmumu, karnauba ve kandelila vakslar1 (mumları) kullanılarak oleojeller oluşturulmuş ve bu oleojellerin bisküvilerde şortening yerine kullanımları araştırılmıştır. Bisküvilerin renk ve tekstürel özellikleri ile oleojellerin yağ bağlama kapasiteleri incelenmiştir.

\section{MATERYAL VE YÖNTEM \\ Materyal}

Araştırmada kullanılan yüksek oleik asit içerikli ayçiçek yağı, Trakya Birlik (Edirne, Türkiye) ve keten tohumu yağı ise Zade Vital A.Ş (Konya, Türkiye)'den temin edilmiştir. Balmumu, karnauba vaks ve kandelila vaks, Gustav Heess Oleochemische Erzeugnisse GmbH (Leonberg, Almanya) firmasından temin edilmiştir.

Bisküvi üretiminde kullanılan buğday unu, sodyum bikarbonat, amonyum bikarbonat ve şortening yerel üreticiler tarafindan sağlanırken, diğer malzemeler yerel marketten satın alınmıştır.

\section{Oleojellerin Hazırlanması}

Oleojellerin hazırlanması için, yüksek oleik asitli ayçiçek yağ1 ve keten tohumu yağına \%10 oranında balmumu (BM), karnauba vaksı $(\mathrm{KV})$ ve kandelila vaksı (KLV) eklenmiş, karışım $120^{\circ} \mathrm{C}$ 'de 15 dakika boyunca karıştırılarak homojen hale getirilmiştir. Sonrasında bu karışımlar oda sıcaklığında katılaşana kadar bekletilmiştir.

\section{Oleojellerin Yă̆ Bağlama Kapasitesinin Belirlenmesi}

Oleojellerin yağ bağlama kapasitesi, Giacomozzi (2019) tarafindan geliştirilen yönteme göre yapılmıştır. Bu amaçla, $1 \mathrm{~g}$ oleojel örneği önceden tartılmış eppendorf tüpüne koyulup 1 saat buzdolabında $\left(4^{\circ} \mathrm{C}\right)$ bekletilmiştir. Sonrasında eppendorf tüpleri oda sıcaklığında 15 dakika bekletildikten sonra 9000 g'de 15 dakika santrifüjlenmiş ve ayrılan yağ uzaklaştırıldıktan sonra tüpler tekrar tartılmıştır. Yağ bağlama kapasitesi (\%) aşağıda verilen formüle göre hesaplanmıştır.

YBK $(\%)=100-\left(\frac{\text { Ayrllan yă̆ miktarl }(g)}{\text { Oleojel miktarl }(g)} \times 100\right)$

\section{Bisküvi Üretimi}

Bisküvi üretiminde AACC Standart No:10-54 üretim metodu modifiye edilerek kullanılmıştır. (AACC, 2000). Formülasyonda $35 \mathrm{~g}$ toz şeker, 32 $\mathrm{g}$ şortening, $1 \mathrm{~g}$ tuz, $0.8 \mathrm{~g}$ yağsız süttozu, $0.8 \mathrm{~g}$ sodyum bikarbonat, $0.4 \mathrm{~g}$ amonyum bikarbonat, 
$1.2 \mathrm{~g}$ yüksek fruktozlu misır şurubu, $80 \mathrm{~g}$ un ve düzgün hamur yapısı elde edilebilmek için 17.6 gram su kullanılmıştır. Bu bileşenleri karıştırma sıras1, hamur kalitesini, şekillendirmeyi ve pişirmeyi oldukça etkilemektedir. $\mathrm{Bu}$ amaçla, öncelikle şortening ve şeker bir mikser (Kitchenaid, Model 5KSM150, Amerika) yardımı ile karıştırılmış, sonrasında karışıma tuz, sodyum bikarbonat ve süt tozu eklenmiştir. Karıştırma işlemi, 1 dakikalık 3 aşamada gerçekleştirilmiştir. Sonrasında suda çözündürülmüş amonyum bikarbonat ve yüksek fruktozlu mısır şurubu eklenmiş ve tekrar 20 saniyelik 3 kez karıştırma işlemine tabi tutulmuştur. Son aşamada un eklenerek karışım 10 saniye süresince $3 \mathrm{kez}$ karıştırılmıştır. Her karıştırma aşamasından sonra, hamur, miksere yapışan kısımlardan sıyrılarak, homojen bir karıştırma işlemi gerçekleştirilmiştir. Yoğurma sonrasi elde edilen hamura, $5 \mathrm{~cm}$ çapında ve $3 \mathrm{~mm}$ yüksekliğinde sabit kesme kalıpları ile şekil verilmiş ve ardından bu hamur parçaları $200{ }^{\circ} \mathrm{C}$ 'de 8 dakika süreyle firında (Memmert UNE 400, Almanya) pişirilmiştir (Van Der Fels-Klerx vd., 2014). Pişirme sonrasında bisküvi örnekleri oda sıcaklı̆̆ına soğutulmuş ve ilgili analizler gerçekleştirilmiştir.

Bisküvilerin kompozisyonunda yer alan şortening yerine $\% 50$ veya $\% 100$ oraninda oleojel kullanılmıştır. Bisküviler, 10 farklı formülasyonda hazırlanmış ve bu formülasyonlar Çizelge 1'de verilmiştir.

Çizelge 1. Bisküvi hazırlanmasında kullanilan hamur formülasyonları Table 1. Dough formulations used in biscuit preparation

\begin{tabular}{|c|c|c|}
\hline \multicolumn{3}{|c|}{$\begin{array}{l}\text { Hamur içersindeki oranı } \\
\text { Ratio in the dough formulation }\end{array}$} \\
\hline Örnek adı & Şortening & Oleojel \\
\hline Sample name & Shortening & Oleogel \\
\hline Kontrol & $\% 100$ & - \\
\hline B-1 & $\% 50$ & \%50 keten yağ1 (B-M) \\
\hline B-2 & $\% 50$ & \%50 keten yağı (KL-V) \\
\hline B-3 & $\% 50$ & \%50 keten yağ1 (K-V) \\
\hline B-4 & $\% 50$ & \%50 ayçiçek yağı (B-M) \\
\hline B-5 & $\% 50$ & \%50 ayçiçek yağ $(\mathrm{K}-\mathrm{V})$ \\
\hline B-6 & $\% 50$ & $\% 50$ ayçiçek yağ $(\mathrm{KL}-\mathrm{V})$ \\
\hline B-7 & - & $\% 100$ ayçiçek yağı (B-M) \\
\hline B-8 & - & \%100 ayçiçek yağı $(\mathrm{K}-\mathrm{V})$ \\
\hline B-9 & - & $\% 100$ ayçiçek yağ1 (KL-V) \\
\hline
\end{tabular}

Bisküvilerin pişirme sırasında yayılma oranı Bisküvi örneklerinin çap ve kalınlık değerleri, AACC (2000)'de belirtildiği şekilde 10-54.01 nolu metoda göre dijital kumpas ( $0.001 \mathrm{~mm}$, Mitutoyo, Tokyo, Japan) kullanılarak ölçülmüştür. Bisküvilerin çap (mm) ve kalınlık (mm) değerleri belirlendikten sonra, yayılma oranı; bisküvi çaplarının ( $\mathrm{mm})$ kalınlıklarına ( $\mathrm{mm})$ oranlanmasıyla elde edilmiştir.

\section{Bisküvilerde Tekstür Profil Analizi}

Bisküvilerin tekstürel özelliklerinin belirlenmesinde tekstür analiz cihazı (TA.XT Plus, Stable Micro Systems, UK) kullanılmış olup,
3 nokta kirlma testi (three point bend rig) tekniğine göre sertlik $(\mathrm{N})$ ve kırılabilirlik $(\mathrm{mm})$ değerleri tespit edilmiştir. Uygulama parametreleri Ayed vd (2021)'e göre belirlenmiş olup, ön-test hizı: $1.0 \mathrm{~mm} \mathrm{~s}-1$, test hiz1: $3.0 \mathrm{~mm} \mathrm{~s}$ 1, son-test hizı: $10.0 \mathrm{~mm} \mathrm{~s}-1$, uzaklik: $5 \mathrm{~mm}$, trigger kuvveti: $0.5 \mathrm{~N}$ olarak uygulanmıştır.

\section{Bisküvilerde renk analizi}

Bisküvilerde renk analizi amacıyla, bisküviler sabit ışık altında dijital olarak fotoğraflanmıştır. Elde edilen fotoğraflar sıkıştırılmadan JPEG formatında kullanılmıştır. Renk ölçümleri $\left(\mathrm{L}^{*} \mathrm{a}^{*} \mathrm{~b}^{*}\right.$ parametreleri) Gökmen ve Sugut (2007) 
tarafindan geliştirilen dijital görüntü piksel değerlerinin Matlab ile dönüştürülmesi yöntemine göre belirlenmiştir.

\section{İstatistiksel Analiz}

Bisküvi üretimleri üç tekerrürlü ve analizler ise iki paralelli olarak gerçekleştirilmiştir. Analiz sonucunda elde edilen verilere varyans analizi ve önemli bulunan faktörlere ise Tukey-HSD Testi uygulanmıştır. Tüm istatistiki hesaplamalar SPSS 17.0.1 paket programı (SPSS Inc., Chicago, Illinois, US) kullanılarak gerçekleştirilmiş olup değerler ortalama \pm standart sapma şeklinde verilmiştir.

\section{BULGULAR VE TARTIŞMA}

\section{Oleojellerin yağ bağlama kapasitesi}

Farklı oloejellerde elde edilen yă bağlama kapasiteleri Şekil 1'de verilmiştir. Yağ bağlama kapasitesi, oleojellerin karekterizasyonunda önemli bir parametredir. Yağ bağlama kapasitesi, oleojel ağının yağ yapılandırma özelliklerini ve jel stabilitesini temsil etmektedir (Yang vd., 2020; Blach vd., 2016). Oleojeller, \%99 (a/a) oranında yağ içerebildiğinden yağ sızıntısını önlemek için oleojellerin yüksek yağ bağlama kapasitelerine sahip olması gerekmektedir. Ayrıca oleojeller yağ ikameleri olarak kullanilacaksa proses sirasindaki karıştırma, soğutma gibi koşullara da dayanabilmelidirler. Yağ bağlama kapasitesini, jelleştirici olarak kullanılan maddenin moleküler yapıs1, jel oluşturma sırasında elde edilen kristal boyutu ile jeli soğutma hızı etkileyebilmektedir (Blake, 2015). Elde edilen sonuçlar incelendiğinde, kandelila mumunun diğer vakslara kıyasla yağ bağlama kapasitesi keten yağ1 ile oluşturulan oleoejelde $\% 99.75$, ayçiçek yağ ile oluşturulan jelde \%99.33 olarak belirlenmiş ve diğer vakslara kıyasla daha yüksek bulunmuştur. Blake vd. (2014) yaptıkları çalsşmada, farklı bitkisel vakslar (pirinç kepeği vaksı, ayçiçeği vaksı, kandelila ve karnauba vaksı) ile oluşturulan oleojellerin yapısal ve fiziksel özellikleri ile yağ bağlama kapasitesi arasındaki ilişkiyi incelemişlerdir. Çalışma sonuçlarına göre yağ bağlama kapasitesi en yüksek kandelila vaks ile yapılan oleojellerde, sonrasında sirasiyla karnauba vaks, ayçiçeği vaksı ve pirinç kepeği vaksı ile yapılan oleojelllerde bulunmuştur. Kandelila vaks ile yapılan jellerde yağ bağlama kapasitesinin yüksek olmasının nedenini kandelila vaks kristallerinin daha büyük yüzey alanı oluşturmaları ve böylece daha yüksek oranda yağı adsorbe edebilmeleri olarak açıklamışlardır. Ayrıca kandelila vaks kristallerinin pirinç kepeği kristallerine göre yağ içerisinde daha iyi disperse olabildiklerini ve böylece oluşan küresel boşluk alanlarının azaldığı ve oluşan ağ yapisından yağın sızmasının engellendiğini rapor etmişlerdir.

Bisküvilerde çap, kalınlık ve yayılma oranı

Bisküvilerde, çap, kalınlık ve yayılma oranı değerleri bisküvilerin teknolojik kalitesi açısından oldukça önemlidir. Farklı kompozisyonlarla üretilmiş bisküvilere ait çap, kalınlık ve yayılma oranı değerleri Çizelge 2'de verilmiştir. Teknolojik açıdan iyi bir bisküvide çapın geniş olması ve bisküvinin homojen bir yüzeye sahip olmas1 beklenir. Aynı zamanda, yüksek yayılma oranı beklenmektedir (Blanco Canalis vd., 2017; Pareyt ve Delcour, 2008). Kontrol örneklerinde, kalınlık $5.40 \mathrm{~mm}$, çap $54.48 \mathrm{~mm}$ ve yayilma oran 10.12 olarak belirlenmiştir. Örnekler arasinda en yüksek yayilma oran1 B2, B6 ve B9 örneklerinde sirasiyla $11.52 \pm 0.27,11.51 \pm 0.66$ ve $11.50 \pm 0.33$ olarak belirlenmiştir. En yüksek kalınlı değeri $6.68 \pm 0.21 \mathrm{~mm}$ ile B8 örneğinde, en düşük kalınlık değeri ise B6 ve B9 örneklerinde görülmüsstür. Yayılma oranının en düşük olduğu kompozisyon şortening yerine \%100 ayçiçek yağı-karnauba vaksı oleojelinin kullanıldığı kompozisyondur. Kontrol ve \% 50 oleojel $-\% \quad 50$ şortening kullanılmış örneklerin (B2 örneği dışında) kalınlık ve yayılma oranı değerleri arasında önemli bir farklıllk gözlenmemiştir $(P>0.05)$. Kandelila vaks içeren oleojeller ile üretilen bisküvilerde, yayılma oranı diğer bisküvilere kıyasla daha yüksek bulunmuştur. Kandelila vaksın karnauba vaksa kıyasla daha düşük erime noktasına sahip olmasının, pişirme sonucunda bisküvinin yayılma oranını etkilediği düşünülmektedir. 


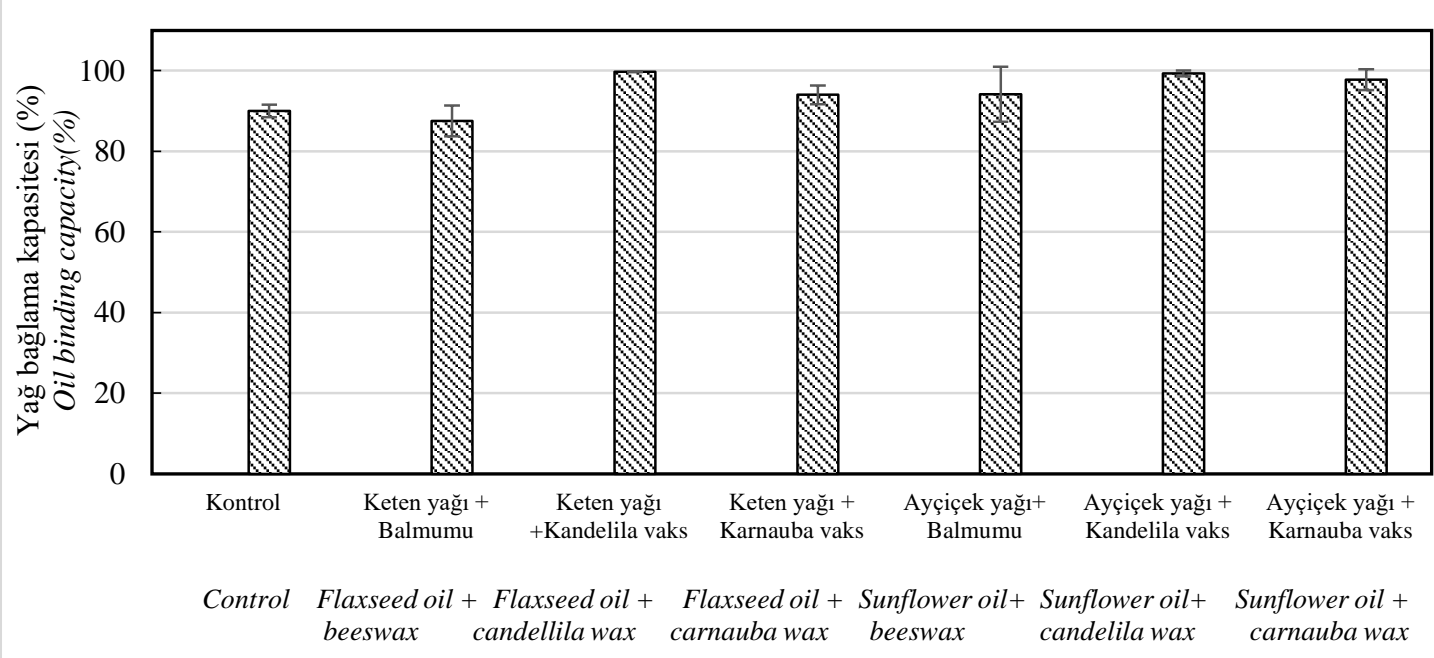

Şekil 1. Oleojellerin yağ bağlama kapasitesi

Figure 1. Oil binding capacity of oleogels

Çizelge 2. Bisküvilerin fiziksel, sertlik ve kırılabilirlik özellikleri

Table 2. Physical properties, hardness and fracturability of biscuits

\begin{tabular}{lccccc}
\hline Örnek Ad1 & $\begin{array}{c}\text { Çap } \\
\text { Diameter } \\
(\mathrm{mm})\end{array}$ & $\begin{array}{c}\text { Kalınlık } \\
\text { Thickness } \\
(\mathrm{mm})\end{array}$ & $\begin{array}{c}\text { Yayllma oran1 } \\
\text { Spread ratio } \\
(\text { Çap/Kalınl1k })\end{array}$ & $\begin{array}{c}\text { Sertlik } \\
\text { Hardness } \\
(\mathrm{N})\end{array}$ & $\begin{array}{c}\text { Kurlabilirlik } \\
\text { Fracturability } \\
(\mathrm{mm})\end{array}$ \\
\hline Kontrol & $54.48 \pm 2.48^{\mathrm{ab}}$ & $5.40 \pm 0.25^{\mathrm{c}}$ & $10.12 \pm 0.82^{\mathrm{b}}$ & $12.08 \pm 0.51^{\mathrm{cd}}$ & $5.12 \pm 0.41^{\mathrm{abc}}$ \\
B-1 & $57.39 \pm 0.40^{\mathrm{cd}}$ & $5.59 \pm 0.14^{\mathrm{c}}$ & $10.27 \pm 0.24^{\mathrm{b}}$ & $7.43 \pm 1.28^{\mathrm{ab}}$ & $5.46 \pm 0.21^{\mathrm{c}}$ \\
B-2 & $58.06 \pm 0.41^{\mathrm{d}}$ & $5.04 \pm 0.10^{\mathrm{b}}$ & $11.52 \pm 0.27^{\mathrm{c}}$ & $5.38 \pm 0.05^{\mathrm{a}}$ & $4.89 \pm 0.05^{\mathrm{abc}}$ \\
B-3 & $55.00 \pm 0.61^{\mathrm{abc}}$ & $5.50 \pm 0.11^{\mathrm{c}}$ & $10.00 \pm 0.19^{\mathrm{b}}$ & $7.69 \pm 1.80^{\mathrm{ab}}$ & $5.31 \pm 0.10^{\mathrm{c}}$ \\
B-4 & $55.53 \pm 0.89^{\mathrm{bc}}$ & $5.55 \pm 0.14^{\mathrm{c}}$ & $10.00 \pm 0.33^{\mathrm{b}}$ & $12.06 \pm 2.71^{\mathrm{cd}}$ & $5.26 \pm 0.19^{\mathrm{bc}}$ \\
B-5 & $55.80 \pm 0.58^{\mathrm{cd}}$ & $5.53 \pm 0.13^{\mathrm{c}}$ & $10.09 \pm 0.29^{\mathrm{b}}$ & $7.27 \pm 2.83^{\mathrm{ab}}$ & $5.50 \pm 0.35^{\mathrm{cd}}$ \\
B-6 & $56.10 \pm 0.46^{\mathrm{cd}}$ & $4.89 \pm 0.30^{\mathrm{ab}}$ & $11.51 \pm 0.66^{\mathrm{c}}$ & $8.46 \pm 0.81^{\mathrm{abc}}$ & $4.62 \pm 0.35^{\mathrm{ab}}$ \\
B-7 & $55.51 \pm 0.34^{\mathrm{bc}}$ & $5.33 \pm 0.13^{\mathrm{c}}$ & $10.41 \pm 0.29^{\mathrm{b}}$ & $12.65 \pm 0.96^{\mathrm{d}}$ & $4.90 \pm 0.10^{\mathrm{abc}}$ \\
B-8 & $53.90 \pm 0.53^{\mathrm{ab}}$ & $6.68 \pm 0.21^{\mathrm{d}}$ & $8.07 \pm 0.32^{\mathrm{a}}$ & $10.71 \pm 1.26^{\mathrm{bcd}}$ & $6.14 \pm 0.22^{\mathrm{d}}$ \\
B-9 & $53.79 \pm 0.55^{\mathrm{a}}$ & $4.68 \pm 0.12^{\mathrm{a}}$ & $11.50 \pm 0.33^{\mathrm{c}}$ & $9.82 \pm 0.1 .62^{\mathrm{bcd}}$ & $4.51 \pm 0.41^{\mathrm{a}}$ \\
\hline
\end{tabular}

İstatistiksel değerlendirme her bir sütun içerisinde yapılmış olup farklı harfler (a, b) ortalamaların $\mathrm{P}<0.05$ düzeyinde farklı olduğunu ifade etmektedir.

Statistical analyses were done in each column and different letters $(a, b)$ indicate significant differences between mean values at $P<0.05$

Li vd. (2021) yaptıkları çalışmada, hidroksipropil metil selüloz (HPMC), monoaçilgliserol, sodyum stearil laktat (SSL), pirinç kepeği vaksı (RBW) ve balmumu (BW) ile oluşturulmuş oleojellerin bisküvide kullanımını araştırmışlardır. Çalışma sonuçlarına göre HPMC kullanılarak yapılan bisküvilerin yayılma oranı en düşük bulunurken SSL, RBW ve BW ile yapılan bisküvilerde yayılma oranı şorteninge göre daha yüksek bulunmuştur. Araştırmacilar bu durumun SSL, RBW ve BW oleojellerinin karıştırma sırasında sıvılaşmasına ve pişirme sırasında hamurun daha az yapışkan özellik göstermesi sonucunda yayılmanın önlendiği ile ilişkilendirmişlerdir. Ayrıca keten tohumu yağını şorteningle farklı oranlarda ikame eden ve bisküvi özelliklerini inceleyen başka bir çalışmada, hamur viskozitesinin pişirme sırasındaki yayılma oranını etkilediği, keten tohumu yağı içeren hamurun viskozitesinin yeterince yüksek olmadığı için yayılmayı durdurmadığı ve yayılma oranında artış gözlendiği rapor edilmiştir (Rangrej vd., 2015). 
Bisküvilerde tekstür (sertlik ve kırılabilirlik) Bisküvi örneklerine ait sertlik ve kırlabilirlik değerleri Çizelge 2'de verilmiştir. Bisküvilerde sertlik değeri, tüketiciler için oldukça önemlidir. Sertlik değeri tüketicinin tazelik algısını etkilemekte ve bisküvinin deformasyona karş1 gösterdiği direnç olarak tanımlanmaktadır (Ahlborn vd., 2005). Elde edilen sonuçlara göre bisküvi örneklerinin sertlik değerlerinin $5.3 \mathrm{~N}$ 12.7 N aralığında değişim göstermektedir. Kontrol bisküvi örneğinde sertlik değeri $12.08 \pm 0.51 \mathrm{~N}$ iken, formülasyona ilave edilen oleojele bağlı olarak sertlik değeri değişkenlik göstermiştir. Kontrol örneğine en yakın sertlik değeri B4 ve B7 örneklerinde sirasıyla 12.06 \pm 2.71 $\mathrm{N}$ ve $12.65 \pm 0.96 \mathrm{~N}$ olarak belirlenmiş ve bu örnekler arasında istatistiksel açıdan önemli bir fark gözlenmemiştir $\quad(P>0.05)$. B4 örneği kompozisyonunda $\% 50$ şortening ile $\% 50$ ayçiçek yağ1-balmumu oleojeli içermektedir. B7 örneğinde ise şortening yerine tamamen ayçiçek yağ1balmumu ile yapılan oleojel kullanılmıştır. \%100 ayçiçek-balmumu oleojeli kullanımının, yapısal özellikler açısından şortening alternatifi olarak kullanılabileceği gözlenmiştir. Karnauba ve kandelila vaks ile üretilen oleojellerin kullanıldığı bisküvilerde sertlik değeri kontrole göre daha düşük tespit edilmiştir. Bisküvi ve benzeri ürünlerin bileşiminde şortening bulunmadığında ya da azaltıldığında, gluten ve nişasta tanecikleri arasında etkileşim artmakta, bu nedenle de sert bir yap1 oluşmaktadır. Yağ miktarı yüksek olduğunda ise, yağ faz oluşturarak gluten ve nişasta yapısının sürekliliğini bozmakta, protein ve nişasta granüllerini çevreleyerek, birbirinden izole etmekte ve ürünün yapısının daha gevrek, kolay parçalanabilir olmasına neden olmaktadır (Akan, 2004; Coşkun, 2020). Bisküvilerde önemli bir diğer parametre de kirllabilirliktir. Kontrol örneklerinde kırılabilirlik değeri $5.12 \pm 0.41 \mathrm{~mm}$ elde edilmiş ve kompozisyonunda \%50 oleojel$\% 50$ şortening olan bisküvilerin kırılabilirlik değerleri ile önemli bir fark gözlenmemiştir. Kontrol örneğine göre önemli bir fark sadece B8 bisküvisinde gözlenmiş ve bu örnekte kırılabilirlik değeri $6.14 \pm 0.22 \mathrm{~mm}$ olarak tespit edilmiștir. Elde edilen sonuçlara göre bisküvilerde oleojel kullanımı ve oleojel yapımında kullanılan vakslar, bisküvinin sertlik ve kırılabilirlik özelliklerini önemli ölçüde etkilemiştir.

\section{Renk analizi}

Bisküvilerin renk analizi sonuçları Çizelge 3'de, dijital fotoğrafları ise Şekil 2'de verilmiştir. Bisküvilerin $L^{*}$ ve $a^{*}$ değerlerinde kontrol bisküvisine göre istatistiksel olarak önemli bir değişiklik gözlemlenmemiştir. Ancak $\mathrm{b}^{*}$ değeri incelendiğinde, 39.71 ile 45.57 arasında değiştiği görülmektedir. Elde edilen sonuçlara göre, bisküvilerin renk özelliklerinin oleojel kullanımı ve kompozisyonundan etkilenmediği sonucuna ulaşılmıştır.

Çizelge 3. Bisküvilerin $\mathrm{L}^{*}, \mathrm{a}^{*}, \mathrm{~b}^{*}$ renk değerleri

Table 3. $L^{*}, a^{*}, b^{*}$ color parameters of biscuits

\begin{tabular}{lccc}
\hline $\begin{array}{l}\text { Örnek Ad1 } \\
\text { Sample name }\end{array}$ & $\mathrm{L}^{*}$ & $\mathrm{a}^{*}$ & $\mathrm{~b}^{*}$ \\
\hline Kontrol & $84.69 \pm 1.16^{\mathrm{a}}$ & $9.49 \pm 1.08^{\mathrm{a}}$ & $44.57 \pm 0.67 \mathrm{~cd}$ \\
B-1 & $82.29 \pm 1.07^{\mathrm{ab}}$ & $12.44 \pm 1.76^{\mathrm{a}}$ & $44.47 \pm 0.85^{\mathrm{cd}}$ \\
B-2 & $82.40 \pm 0.16^{\mathrm{ab}}$ & $11.26 \pm 0.32^{\mathrm{a}}$ & $45.57 \pm 0.10^{\mathrm{d}}$ \\
B-3 & $82.37 \pm 0.57^{\mathrm{ab}}$ & $12.01 \pm 0.97^{\mathrm{a}}$ & $41.65 \pm 1.17^{\mathrm{ab}}$ \\
B-4 & $82.99 \pm 1.00^{\mathrm{ab}}$ & $11.59 \pm 1.34^{\mathrm{a}}$ & $40.48 \pm 0.96^{\mathrm{a}}$ \\
B-5 & $83.63 \pm 0.88^{\mathrm{ab}}$ & $10.69 \pm 1.01^{\mathrm{a}}$ & $39.71 \pm 0.29^{\mathrm{a}}$ \\
B-6 & $83.88 \pm 0.96^{\mathrm{a}}$ & $10.23 \pm 1.24^{\mathrm{a}}$ & $39.85 \pm 1.04^{\mathrm{a}}$ \\
B-7 & $80.04 \pm 0.95^{\mathrm{b}}$ & $13.26 \pm 0.92^{\mathrm{a}}$ & $43.46 \pm 0.87_{\mathrm{bcd}}^{\mathrm{a}}$ \\
B-8 & $81.68 \pm 1.62^{\mathrm{ab}}$ & $12.09 \pm 1.52^{\mathrm{a}}$ & $42.08 \pm 0.61^{\mathrm{abc}}$ \\
B-9 & $82.40 \pm 2.72^{\mathrm{ab}}$ & $11.81 \pm 3.36^{\mathrm{a}}$ & $40.47 \pm 1.34^{\mathrm{a}}$ \\
\hline
\end{tabular}

İstatistiksel değerlendirme her bir sütun içerisinde yapılmış olup farklı harfler $(\mathrm{a}, \mathrm{b})$ ortalamaların $\mathrm{P}<0.05$ düzeyinde farklı olduğunu ifade etmektedir.

Statistical analyses were done in each column and different letters $(a, b)$ indicate significant differences between mean values at $P<0.05$ 

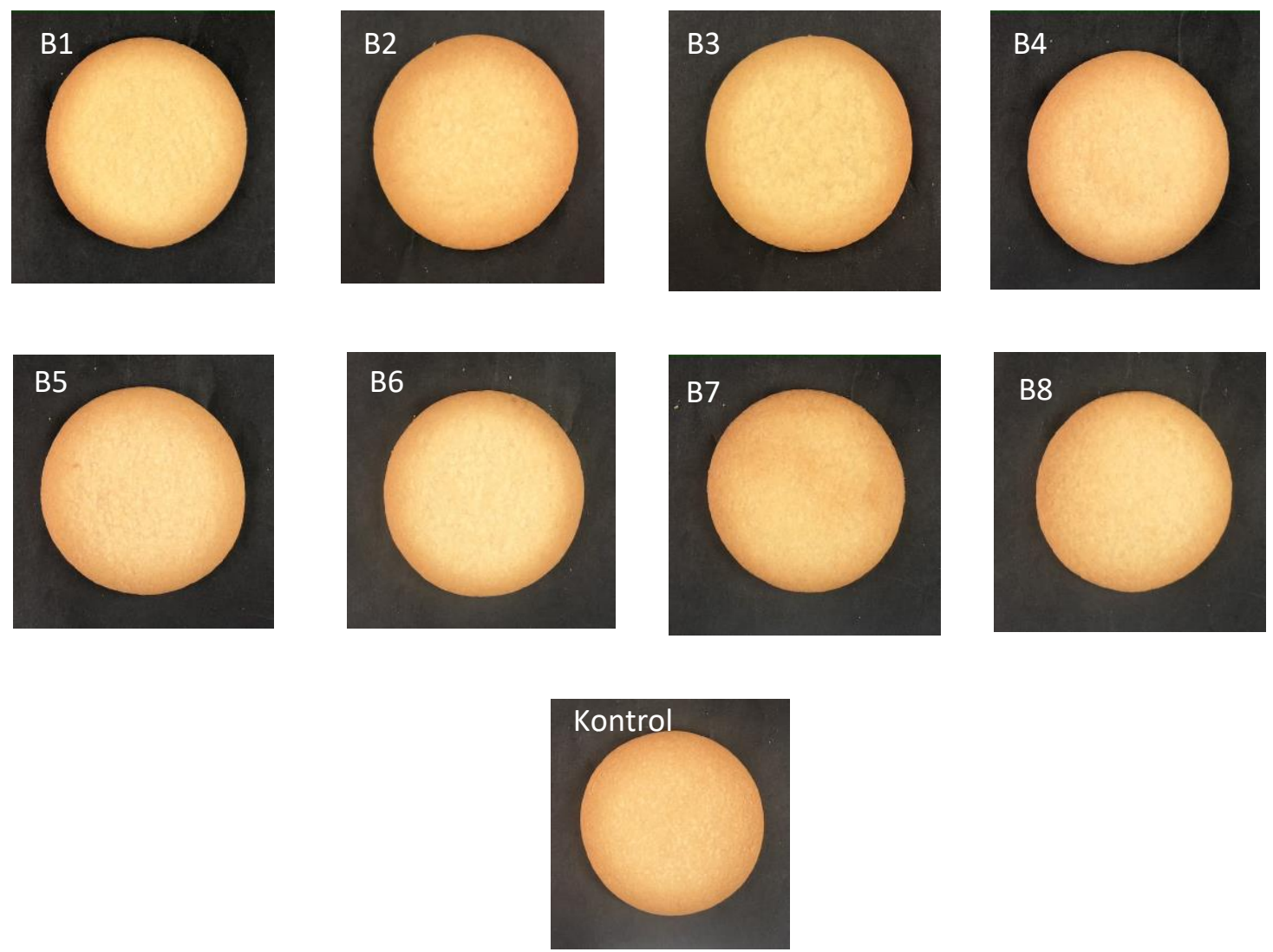

Şekil 2. Farklı olojeller kullanılarak yapılmış bisküvilerin görüntüleri

Figure 2. Images of biscuits produced by using different oleogels

\section{SONUÇ}

$\mathrm{Bu}$ çalışma sonucunda balmumu, kandelila, karnauba vaksı kullanılarak keten ve ayçiçek yağı oleojelleri üretilmiş ve bu oleojellerin şortening yerine bisküvide kullanım olanakları araştırılmışır. Şortening yerine oleojel kullanımı bisküvilerin renk özelliklerini önemli derecede etkilemezken, tekstürel özelliklerinde farklilıklara yol açmıştır. Özellikle sertlik değerlerinde önemli farkllıklar görülmüş, kontrol örneğine en yakın bulunan sertlik değerleri $\% 50$ ayçiçek yağ1balmumu oleojeli ve $\% 50$ şortening ile üretilen bisküvilerde belirlenmiştir. Ayrıca şortening yerine tamamen ayçiçek yağı-balmumu oleojeli ile üretilen bisküvilerde de sertlik ve kır1labilirlik değerlerinde kontrol bisküvisine kıyasla önemli bir fark gözlenmemiştir. Keten tohumu yağı ile üretilen oleojellerde de yapisal problemler gözlenmemiş ancak bisküvilerin tat-koku gibi özelliklerinin olumsuz etkilenebileceği sonucuna ulaşılmıştır. Ayrıca keten tohum yağı gibi çoklu doymamış yağ asiti ile olușturulan oleojellerin oksidasyona açık olmasından dolayı bisküvi raf ömrünü olumsuz etkilebileyeceği öngörülmüştür. $\mathrm{Bu}$ bakımdan oleojellerin gida ürünlerinde kullanım olanaklarının değerlendirilmesi amacıyla, gelecek çalışmalarda oleojel stabilitesinin belirlenmesi ve üründe raf ömrü analizlerinin yapılması gerekliliği sonucuna ulaşılmışır.

\section{ÇIKAR ÇATIŞMASI BEYANI}

Yazar, çıkar çatışması olmadığını beyan etmektedir.

\section{KAYNAKLAR}

AACC International. (2000). Approved Methods of the American Association of Cereal Chemists, 
10th Ed. Method 44-19. The Association: St. Paul, $\mathrm{MN}$.

Ahlborn GJ, Pike OA, Hendrix SB, Hess WM, Huber CS. (2005). Sensory, mechanical and microscopic evaluation of staling in low protein and gluten free breads. Cereal Chem, 82: 328- 335.

Akan T. (2004). Kek üretiminde kullanilan interesterifiye yağların kek kalitesine etkisi. Yüzüncü Yıl Üniversitesi Fen bilimleri Enstitüsü Gıda Mühendisliği Anabilim Dalı Yüksek lisans tezi, Van, Türkiye, $30 \mathrm{~s}$.

Ayed, C., Lim, M., Nawaz, K., Macnaughtan, W., Sturrock, C. J., Hill, S. E., Linforth R., Fisk, I. D. (2021). The role of sodium chloride in the sensory and physico-chemical properties of sweet biscuits. Food Chem: X, 9, 100115.

Blach, C., Gravelle, A. J., Peyronel, F., Weiss, J., Barbut, S., Marangoni, A. G. (2016). Revisiting the crystallization behavior of stearyl alcohol : stearic acid (SO : SA) mixtures in edible oil. RSC Advances, 6(84), 81151-81163.

Blake, A.I., Co, E.D.,Marangoni, A.G. (2014). Structure and Physical Properties of Plant Wax Crystal Networks and Their Relationship to Oil Binding Capacity. J Am Oil Chem Soc, 91: 885-903.

Blake, A.I.E. (2015). The Microstructure and Physical Properties of Plant-Based Waxes and their Relationship to the Oil Binding Capacity of Wax Oleogels. Msc.Dissertation, The University of Guelph Guelph, Ontario, Canada, 173p.

Blanco Canalis, M.S., Steffolani, M.E., León, A.E., Ribotta, P.D. (2017). Effect of different fibers on dough properties and biscuit quality. $J$ Sci Food Agr, 97, 1607-1615.

Brouwer I. A., Wanders A. J., Katan M. B. (2010). Effect of animal and industrial trans fatty acids on HDL and LDL cholesterol levels in humans-a quantitative review, PLoS One, 2;5(3):e9434.

Coşkun M. (2020). Bisküvide yağ ikamesi olarak kahve çekirdeği zarı kullanımı.Uludağ Üniversitesi Fen Bilimleri Enstitüsü Gıda Mühendisliği Anabilim Dalı Yüksek lisans tezi, Bursa, Türkiye, 90s.
Da Silva, S. L., Amaral, J. T., Ribeiro, M., Sebastiao, E. E., Vargas, C., de Lima Franze, F.,... Campagnol, P. C. B. (2019). Fat replacement by oleogel rich in oleic acid and its impact on the technological, nutritional, oxidative, and sensory properties of Bologna-type sausages. Meat Sci, 149, 141-148.

Demirkesen, I., Mert, B. (2019). Utilization of Beeswax Oleogel-Shortening Mixtures in GlutenFree Bakery Products. J American Oil Chem Soc, 96 (5), 545-554.

Giacomozzi, A.S., Palla, C.A., Carrín, M.E., Martini, S. (2019). Physical Properties of Monoglycerides Oleogels Modified by Concentration, Cooling Rate, and High-Intensity Ultrasound. J Food Sci, 84: 2549-2561.

Gökmen, V., Sugut, I. (2007). A Non-Contact Computer Vision Based Analysis of Color in Foods. Int J Food Eng, 3 (5).

Hughes, N. E., Marangoni, A. G., Wright, A. J., Rogers, M. A., Rush, J. W. E. (2009). Potential food applications of edible oil organogels. Trends in Food Sci \& Technol, 20 (10), 470-480.

Iqbal, S., Xu, Z., Huang, H., Chen, X. D. (2019). Controlling the rheological properties of oil phases using controlled protein-polysaccharide aggregation and heteroaggregation in water-in-oil emulsions. Food Hydrocoll, 96, 278-287.

Jang, A., Bae, W., Hwang, H. S., Lee, H. G., Lee, S. (2015). Evaluation of canola oil oleogels with candelilla wax as an alternative to shortening in baked goods. Food Chem, 187, 525-529.

Li, S., Wu, G., Li, X., Jin, Q., Wang, X., Zhang, H. (2021). Roles of gelator type and gelation technology on texture and sensory properties of cookies prepared with oleogels. Food Chem, 356, 129667.

Mert, B., Demirkesen, I. (2016). Reducing saturated fat with oleogel/shortening blends in a baked product. Food Chem, 199, 809-816.

Mozaffarian, D., Aro, A., Willett, W. C. (2009). Health effects of trans-fatty acids: experimental and observational evidence. Eur J Clin Nutr, 63 Suppl 2, S5-21. 
Ögütcü, M., Yllmaz, E. (2015). Characterization of hazelnut oil oleogels prepared with sunflower and carnauba waxes. Int J Food Prop, 18 (8), 17411755.

Pareyt, B., Delcour, J. A. (2008). The Role of Wheat Flour Constituents, Sugar, and Fat in Low Moisture Cereal Based Products: A Review on Sugar-Snap Cookies. Crit Rev Food Sci Nutr, 48 (9), 824-839.

Park, C., Maleky, F. (2020). A Critical Review of the Last 10 Years of Oleogels in Food. Front Sust Food Syst, 4(139).

Patel, A., Dewettinck, K. (2016). "Edible oil structuring: an overview and recent updates", Food and Funct, 7, 20-29.

Pehlivanoğlu, H., Demirci, M., Toker, O. S., Konar, N., Karasu, S., Sagdic, O. (2018). Oleogels, a promising structured oil for decreasing saturated fatty acid concentrations: Production and food-based applications. Crit Rev Food Sci Nutr, 58 (8), 1330-1341.

Pérez-Monterroza, E. J., Márquez-Cardozo, C. J., Ciro-Velásquez, H. J. (2014). Rheological behavior of avocado (Persea americana Mill, cv. Hass) oleogels considering the combined effect of structuring agents. LWT - Food Sci Technol, 59(2, Part 1), 673-679.

Rangrej, V., Shah, V., Patel, J., Ganorkar, P.M.(2015). Effect of shortening replacement with flaxseed oil on physical, sensory, fatty acid and storage characteristics of cookies. J Food sci Technol, 52 (6), 3694-3700.
Singh, A., Auzanneau, F. I., Rogers, M. A. (2017). Advances in edible oleogel technologies - A decade in review. Food Res Int, 97, 307-317.

Vaclavik V. A., Christian E. W. (2014). Fat and Oil Products in Essentials of Food Science. 4th edition, Food Science Text Series. Springer, New York, USA, 495 p.

Van Der Fels-Klerx, H. J., Capuano, E., Nguyen, H. T., Ataç Mogol, B., Kocadağl1, T., Göncüoğlu Taş, N., Hamzalıoğlu A., Van Boekel, M.A.J.S., Gökmen, V. (2014). Acrylamide and 5hydroxymethylfurfural formation during baking of biscuits: $\mathrm{NaCl}$ and temperature-time profile effects and kinetics. Food Res Int, 57, 210-217.

Uauy, R., Aro, A., Clarke, R., Ghafoorunissa, L'Abbé, M. R., Mozaffarian, D., Skeaf, C.M., Stender S., Tavella, M. (2009). WHO Scientific Update on trans fatty acids: summary and conclusions. Eur J Clin Nutr, 63 (2), S68-S75.

Yang, S., Yang, G., Chen, X., Chen, J., Liu, W. (2020). Interaction of monopalmitate and carnauba wax on the properties and crystallization behavior of soybean oleogel. Grain Oil Sci Technol, 3(2), 49-56.

Zetzl, A. K., Marangoni, A. G., Barbut, S. (2012). Mechanical properties of ethylcellulose oleogels and their potential for saturated fat reduction in frankfurters. Food Funct, 3 (3), 327-337. 